\title{
Polyetheretherketone Cage with Demineralized Bone Matrix Can Replace Iliac Crest Autografts for Anterior Cervical Discectomy and Fusion in Subaxial Cervical Spine Injuries
}

\author{
Soo-Han Kim, M.D., ${ }^{*}$ Jung-Kil Lee, M.D.,, Jae-Won Jang, M.D.,, ${ }^{1,2}$ Hyun-Woong Park, M.D., ${ }^{1}$ Hyuk Hur, M.D. \\ Department of Neurosurgery, Chonnam National University Medical School \& Research Institute of Medical Sciences, Gwangju, Korea \\ Department of Neurosurgery, ${ }^{2}$ Happy-view Samsung Hospital, Gwangju, Korea
}

Objective : This study aimed to compare the clinical and radiologic outcomes of patients with subaxial cervical injury who underwent anterior cervical discectomy and fusion (ACDF) with autologous iliac bone graft or polyetheretherketone (PEEK) cages using demineralized bone matrix (DBM).

Methods : From January 2005 to December 2010, 70 patients who underwent one-level ACDF with plate fixation for posttraumatic subaxial cervical spinal injury in a single institution were retrospectively investigated. Autologous iliac crest grafts were used in 33 patients (Group I), whereas 37 patients underwent ACDF using a PEEK cage filled with DBM (Group II). Plain radiographs were used to assess bone fusion, interbody height (IBH), segmental angle (SA), overall cervical sagittal alignment (CSA, C2-7 angle), and development of adjacent segmental degeneration (ASD). Clinical outcome was assessed using a visual analog scale (VAS) for pain and Frankel grade.

Results : The mean follow-up duration for patients in Group I and Group II was 28.9 and 25.4 months, respectively. All patients from both groups achieved solid fusion during the follow-up period. The IBH and SA of the fused segment and CSA in Group II were better maintained during the follow-up period. Nine patients in Group I and two patients in Group II developed radiologic ASD. There were no statistically significant differences in the VAS score and Frankel grade between the groups.

Conclusion : This study showed that PEEK cage filled with DBM, and plate fixation is at least as safe and effective as ACDF using autograft, with good maintenance of cervical alignment. With advantages such as no donor site morbidity and no graft-related complications, PEEK cage filled with DBM, and plate fixation provide a promising surgical option for treating traumatic subaxial cervical spine injuries.

Key Words : ACDF · DBM · lliac autograft · PEEK cage · Subaxial cervical spine injury.

\footnotetext{
- Received : March 6, 2016 •Revised : November 15, 2016 •Accepted : December 15, 2016

- Address for reprints : Jae-Won Jang, M.D.

Department of Neurosurgery, Chonnam National University Hospital, 42 Jaebong-ro, Dong-gu, Gwangju 61469, Korea Tel : +82-62-220-6603, Fax : +82-62-224-9865, E-mail : genius60@hanmail.net

*These authors contributed equally to this project and should be considered as co-first authors
} 


\section{INTRODUCTION}

The main principles in the treatment of unstable cervical spine injuries are reduction and stabilization of the injured segment. Early surgery offers the best chance to achieve optimal reduction, immediate stability, minimum external fixation, and direct decompression of the cord and the exiting roots, providing an opportunity for neurological recovery ${ }^{1)}$. Moreover, surgery can enable early mobilization and avoid complications associated with prolonged bed rest, such as pneumonia, deep vein thrombosis, or bed sore. Anterior cervical discectomy and fusion (ACDF) with plate stabilization is widely employed with a high success rate of reduction and good clinical results for unstable subaxial cervical spine injuries $^{21)}$. An anterior approach enables the surgeon to decompress the spinal canal by removing the disc and, thus, avoid neurologic deterioration by further disc displacement ${ }^{11,24)}$.

Selection of appropriate graft substrate is essential to achieve bone fusion and an optimal clinical outcome. Although autograft has been considered the gold standard for ACDF, the immediate and long-term morbidity associated with iliac crest harvesting cannot be ignored. The incidence of donor site morbidity including chronic pain, hematoma, infection, injury to adjacent nerves, visceral herniation, and iliac crest fracture has been reported to be as high as $20-30 \%{ }^{177}$. Recently, the use of synthetic cages for ACDF has become increasingly popular. However, the fusion rates for ACDF with additional plating compared with those using autograft to synthetic cages have not been adequately addressed for traumatic injury cases. This study aimed to identify the differences in the efficacy of the two commonly used fusion materials, namely tricortical iliac crest autograft and synthetic cage with demineralized bone matrix (DBM) in patients who underwent singlelevel ACDF with plate fixation for traumatic subaxial cervical injury.

\section{MATERIALS AND METHODS}

This retrospective study was based on a review of hospital charts, operative notes, and clinical and radiographic followup data of outpatients. Patients or their guardians provided written informed consent to submit their medical information to the journal. Institutional review board/ethics commit- tee approval was obtained from the Institutional Review Board of the Chonnam National University Hospital (IRB No. : CNUH-2016-261).

\section{Patient population}

The medical records of 70 patients who underwent one-level ACDF with plate fixation for post-traumatic subaxial cervical spinal injury and who underwent at least 24 months of followup in a single institution from January 2005 to December 2010 were retrospectively investigated. Patients with a single-level distractive or compressive subaxial spine injury with or without spinal cord injury were included. Patients with a history of neck surgery, acute infectious disease, osteoporosis, vertebral body injury, multiple level injuries and/or those requiring posterior cervical instrumentation were excluded.

Based on the type of the applied graft material, the patients were divided into two groups. Group I consisted of 33 patients who underwent fusion using autologous iliac crest grafts between January 2005 and December 2007, while Group II consisted of 37 patients who underwent fusion using a polyetheretherketone (PEEK; Solis, Stryker Spine South Allendale, NJ, USA) cage with DBM (Grafton, Osteotech, Inc., Shrewsbury, NJ, USA) between January 2008 and December 2010.

C3-4 were affected in 2 patients, $\mathrm{C} 4-5$ were affected in 7 patients, C5-6 were affected in 13 patients, and C6-7 were affected in 11 patients from Group I. C3-4 were affected in 1 patient, C4-5 were affected in 9 patients, while C5-6 and C6-7 were affected in 15 and 12 patients, respectively, from Group II.

\section{Preoperative management}

All patients included in the study underwent reduction of their subluxation or dislocation in the emergency room. After clinical assessment and radiological evaluation, GardnerWells tongs were applied and traction was started with 10 pounds of weight. The traction weight was gradually increased under neurological monitoring and based on radiological assessments of the degree of subluxation, using lateral cervical spine radiographs, until reduction was achieved or a maximum of 40 pounds of traction was reached. Small doses of narcotics and muscle relaxants were administered when required. If there was any evidence of a spinal cord injury, highdose intravenous methylprednisolone was administered in accordance with the guidelines of the National Acute Spinal 
Cord Injury Study $\mathrm{II}^{4}$. Reduction under general anesthesia was attempted in patients whose subluxation or dislocations could not be reduced with traction. If this was unsuccessful, reduction was completed after discectomy using a standard Smith-Robinson anterior approach. Preoperative skull traction for temporary external stabilization of the injured cervical spine and early surgical intervention was performed within 24 hours after admission in all patients.

\section{Surgical procedure}

Standard anterior transverse incision was performed to expose the involved segment. After discectomy and osteophyte excision under the microscope, the roots or the spinal cord was totally decompressed, and the superior and inferior endplates were prepared for fusion. Bone fragments obtained during resection of osteophytes were collected for grafting. In the autograft group, tricortical iliac bone was harvested from the anterior iliac crest of the patient, using a standardized bone graft harvest technique. The tricortical bone graft was remodeled to fit into the interspace, and inserted into the disc space using the distraction device. In the cage group, microchip bone material was saved as much as possible. PEEK cage was packed with DBM and the local osteophyte-derived bone chip, and inserted into the disc space. Percutaneous pedicle screws (Bk-Meditech, Hwa-sung, Korea) or Zephir (Medtronic Sofamor Danek, Memphis, TN, USA) plate with unicortical titanium screws was used in all patients. Intraoperative fluo- roscopy was performed to confirm appropriate positioning of the graft and to check the alignment of the cervical spine. All patients were instructed to wear the Philadelphia cervical collar for 8 weeks after the operation, and early ambulation or rehabilitation was encouraged.

\section{Radiologic assessment}

Simple plain cervical radiographs were obtained before surgery, immediately after surgery, at 8 weeks, 6 months, and 12 months after surgery, and then annually. Segmental angle (SA) of the fusion level and overall cervical sagittal alignment (CSA, C2-7 angle) were measured using neutral lateral radiographs. To investigate the changes in the interbody height (IBH) of the fused segments, the length between the center of the superior end plate of the cranial vertebral body and the inferior end plate of the caudal vertebral body was measured (Fig. 1). Fusion was defined as less than 2-mm motion between the spinous processes on flexion-extension lateral radiographs, absence of radiolucent gap between the graft and end plate junctions, and the presence of continuous bridging trabeculae at the graft and end plate junctions on simple lateral radiographs or computed tomography (CT) images ${ }^{27)}$. The development of radiologic adjacent segment degeneration (ASD) was investigated using simple lateral radiographs, at 24 months. ASD was defined as narrowing of the disc space with or without posterior osteophytes, new anterior osteophyte formation, or calcification of the anterior longitudinal liga-
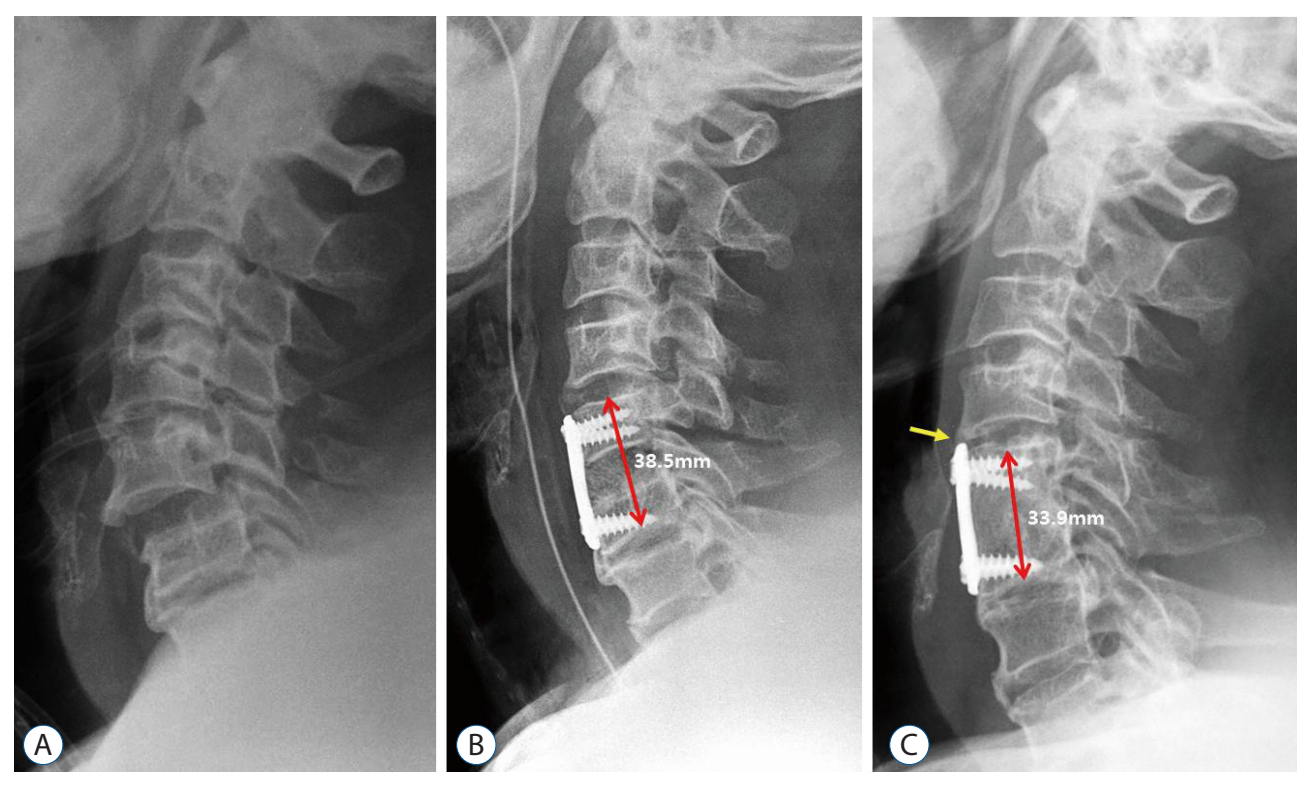

Fig. 1. Imaging studies of a 54-yearold man who underwent a C5-6 anterior cervical fusion using autologous iliac bone graft after subaxial injury. A : Simple cervical lateral radiograph shows (5-6 subluxation and disc space widening with spinous process fracture. B : Postoperative radiograph shows satisfactory reduction of the injured segment after C5-6 fusion with anterior plating. C : Last follow-up radiograph at 24 months after surgery shows satisfactory fusion at the C5-6 level; however, some degrees of subsidence and development of adjacent segment degeneration (yellow arrow) were observed with impingement of the plate to $C 4-5$ disc level. 
ment ${ }^{13)}$. These measurements were performed by a single independent observer who was not involved in the surgery or care of the patients.

\section{Clinical outcome assessment}

Patient statuses were reviewed clinically at 8 weeks and 3, 6, and 12 months after surgery, and then annually. Clinical outcome was assessed using visual analog scale (VAS) scores of neck pain $(0=$ no symptom; $10=$ maximum pain). In Group I, the VAS score of inguinal pain related to bone harvesting was checked during the follow-up period. Neurologic assessment was performed using the Frankel scale : Grade A indicated no motor or sensory function; Grade B indicated sensory function but no motor function; Grade $\mathrm{C}$ indicated useless motor function with sensation; Grade D indicated useful motor function and sensation with some deficit; and Grade E indicated normal motor function and sensation ${ }^{10)}$.

\section{Statistical analysis}

The demographic features, radiographic parameters, and clinical outcomes were compared between the groups. Data were analyzed using the SPSS program for Windows V17.0 (IBM Inc., Chicago, IL, USA); the independent t-test, paired ttest, chi-square test, and Mann-Whitney $U$ test were used for analyses. Data are presented as the mean \pm standard deviation. For all analyses, a $p$-value $<0.05$ was considered statistically significant.

Table 1. Demographic features of patients

\begin{tabular}{lcc}
\hline & Group I & Group II \\
\hline Number & 33 & 37 \\
Mean age (years) & 46.0 & 48.2 \\
Sex (female/male) & $7 / 26$ & $10 / 27$ \\
Injured level & & \\
C3-4 & 2 & 1 \\
C4-5 & 7 & 9 \\
C5-6 & 13 & 15 \\
C6-7 & 11 & 12 \\
Injury mechanism & & \\
Car accident & 23 & 24 \\
Fall & 8 & 9 \\
Slipping & 2 & 4 \\
Mean follow-up period (months) & 28.9 & 25.4 \\
\hline
\end{tabular}

\section{RESULTS}

Group I consisted of 7 men and 26 women, and Group II consisted of 10 men and 27 women. The mean ages of the patients in Group I and Group II were 46.0 years and 48.2 years, respectively. Cervical injury was caused by a car accident in 47 patients (Group I : 23, Group II : 24), fall from a height in 17 (Group I : 8, Group II : 9) patients, and slipping in 6 (Group I : 2, Group II : 4) patients. There was no difference in the demographic features between patients in the two groups. Plain lateral radiographs and cervical CT images with sagittal and coronal reconstruction were obtained in all patients, and they demonstrated subluxation or dislocation at C3-4 in 3 patients (Group I : 2, Group II : 1), at C4-5 in 16 patients (Group I : 7, Group II : 9), at C5-6 in 28 patients (Group I : 13, Group II : 15), and at C6-7 in 23 patients (Group I : 11, Group II : 12). The most common site of dislocation was C5-6. The mean followup period in Group I and Group II was 28.9 months and 25.4 months (range, 24-37 months), respectively (Table 1).

\section{Clinical outcomes}

A summary of neurologic outcomes is provided in Table 2. In Group I, 6 patients (24\%) showed improvement by at least one Frankel grade on the last follow-up, compared with their

Table 2. Neurologic outcomes according to Frankel classification in the iliac bone graft and PEEK cage groups

\begin{tabular}{|c|c|c|c|c|c|c|}
\hline \multirow{2}{*}{\multicolumn{2}{|c|}{ Group I (Iliac graft) }} & \multicolumn{5}{|c|}{ Frankel grade (Last) } \\
\hline & & A & B & $\mathrm{C}$ & D & $E$ \\
\hline \multirow{5}{*}{$\begin{array}{l}\text { Frankel grade } \\
\text { (preoperative) }\end{array}$} & $A$ & 2 & & & & \\
\hline & B & & 3 & & 2 & 1 \\
\hline & C & & & 2 & 5 & 3 \\
\hline & D & & & & 3 & 5 \\
\hline & $E$ & & & & & 7 \\
\hline
\end{tabular}

\begin{tabular}{|c|c|c|c|c|c|c|}
\hline \multirow{2}{*}{\multicolumn{2}{|c|}{$\begin{array}{l}\text { Group II } \\
\text { (Synthetic cage) }\end{array}$}} & \multicolumn{5}{|c|}{ Frankel grade (Last) } \\
\hline & & A & B & C & D & E \\
\hline \multirow{5}{*}{$\begin{array}{l}\text { Frankel grade } \\
\text { (preoperative) }\end{array}$} & $A$ & 1 & & & & \\
\hline & B & & 1 & 1 & & \\
\hline & C & & & 2 & 2 & 1 \\
\hline & $\mathrm{D}$ & & & & 2 & 5 \\
\hline & $E$ & & & & & 15 \\
\hline
\end{tabular}

PEEK : polyetheretherketone 
Table 3. Visual analog scale (VAS) scores for neck and inguinal pain

\begin{tabular}{lccccc}
\hline & \multicolumn{2}{c}{ VAS (neck pain) } & \multicolumn{2}{c}{ VAS (inguinal pain) } \\
\hline & Preoperative value & Final follow-up value & $p$-value & $\begin{array}{c}\text { Immediate } \\
\text { postoperative value }\end{array}$ & Final follow-up value \\
Group I (lliac graft) & $8.6 \pm 2.6$ & $2.9 \pm 1.9$ & $<0.001$ & $7.8 \pm 3.9$ & $3.2 \pm 2.8$ \\
Group II (Cage) & $7.9 \pm 3.2$ & $2.4 \pm 1.8$ & $<0.001$ & None & None \\
$p$-value (II) & 0.27 & 0.35 & 0.48 (overall) & & \\
\hline
\end{tabular}

Values are presented as means \pm standard deviation

preoperative status. In Group II, 6 patients (17\%) showed improvement by at least one Frankel grade on the last follow-up, compared with their preoperative status. The improvement in Frankel grade between the groups was not statistically significant $(p=0.58)$. The mean VAS scores of neck pain in Group I and Group II were 8.6 \pm 2.6 and 7.9 \pm 3.2 , respectively, before surgery and $2.9 \pm 1.9$ and $2.4 \pm 1.8$, respectively, at the final follow-up. The postoperative difference was statistically significant compared with the preoperative score, in both groups $(p<0.001$ in both group, chi-square analysis). However, there was no statistical significance between the groups ( $p=0.48$ between two groups, chi-square analysis). In Group I, the VAS score of inguinal pain was $7.8 \pm 3.9$ after surgery, and the score decreased to $3.2 \pm 2.8$ at 3 months after surgery. However, 8 out of $25(32 \%)$ patients complained of inguinal pain until the last follow-up (Table 3).

\section{Radiographic results}

All 70 patients had undergone complete radiographic follow-up at 1 year after surgery, and solid fusion was evident in all cases, based on the absence of more than 2-mm motion and complete formation of a bony bridge between the graft and the vertebral body, as observed on simple dynamic lateral radiographs. No case of pseudarthrosis was observed in either group. A summary of the radiological outcomes is provided in Table 3. In Group I, the mean preoperative SA was $6.7 \pm 7.7^{\circ}$. The mean local lordosis immediately after surgery was $-3.6 \pm$ $6.6^{\circ}$, and it was $0.6 \pm 7.1^{\circ}$ at the final follow-up. The mean CSA was $-6.7 \pm 14.9^{\circ},-11.7 \pm 11.4^{\circ}$, and $-10.1 \pm 9.1^{\circ}$ at the preoperative, postoperative, and last follow-up. The mean increase in the angle at the final follow-up was $6.1^{\circ}$ and $3.4^{\circ}$ in SA and CSA, respectively. The mean $\mathrm{IBH}$ was $36.6 \pm 4.7 \mathrm{~mm}, 40.4 \pm 5.2 \mathrm{~mm}$, and $37.5 \pm 2.8 \mathrm{~mm}$ preoperatively, postoperatively, and at last follow-up, respectively. The mean increase of IBH at the final follow-up was $0.9 \mathrm{~mm}$ (Fig. 1).

In Group II, the mean preoperative SA was $5.7 \pm 8.1^{\circ}$. The SA immediately after surgery and at the final follow-up was $-5.9 \pm$ $4.7^{\circ}$ and $-4.8 \pm 4.1^{\circ}$, respectively. The mean CSA was $-8.7 \pm 10.1^{\circ}$, $-13.9 \pm 12.0^{\circ}$, and $-15.2 \pm 12.9^{\circ}$ preoperatively, postoperatively, and at the last follow-up. The mean increase in the angle at the final follow-up was $10.5^{\circ}$ and $6.5^{\circ}$ in SA and CSA, respectively. The mean IBH was $36.4 \pm 3.0 \mathrm{~mm}, 41.3 \pm 3.8 \mathrm{~mm}$, and $40.4 \pm 3.3$ $\mathrm{mm}$ preoperatively, postoperatively, and at the last follow-up. The mean increase of IBH at the final follow-up was $4.0 \mathrm{~mm}$. SA, CSA, and IBH were better maintained in Group II than in Group I; in particular, there were statistically significant differences in the maintenance of SA and IBH between the groups (Fig. 2, Table 4).

Nine patients from Group I and two patients from Group II developed radiologic ASD ( $p=0.021)$; however, no patient required additional surgery due to the symptomatic ASD (Table 5).

\section{Procedure-related complications}

No patient in our series developed a hematoma or wound infection after surgery. There were no incidents of vertebral artery injury, recurrent laryngeal nerve palsy, or esophageal or tracheal laceration. During the follow-up period, there were no cases of hardware failure such as migration or breakage. Therefore, no additional surgical procedures were required during the follow-up period.

\section{DISCUSSION}

Because of the high failure rates associated with conservative treatment, surgery is preferred to avoid delayed instability due to incomplete healing of the injured ligaments and pro- 

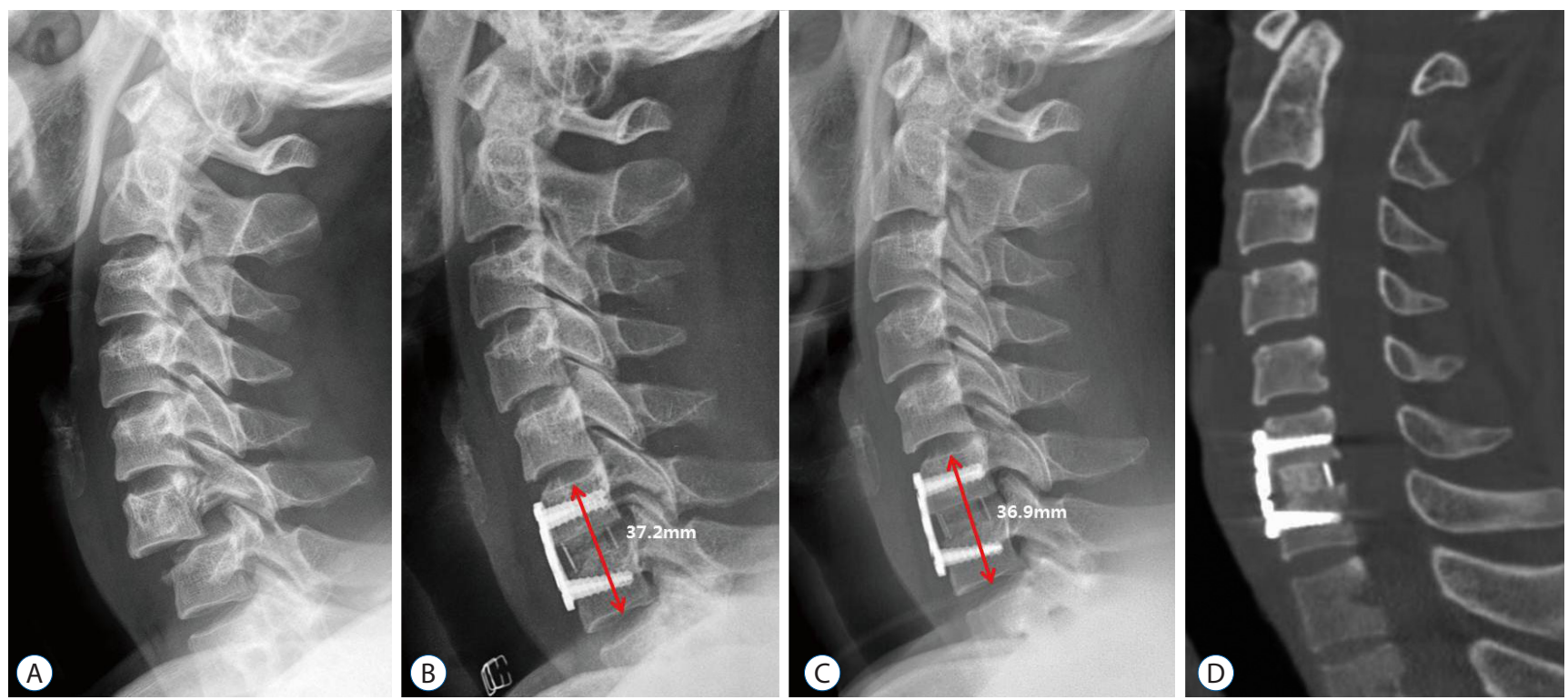

Fig. 2. Imaging studies of a 47-year-old man who underwent C6-7 fusion using a synthetic cage filled with demineralized bone matrix and local osteophytes. A : Simple cervical lateral radiograph shows C6-7 subluxation and disc space widening. B : Postoperative radiograph shows satisfactory reduction of the injured segment after C6-7 fusion. C : Last follow-up radiograph at 24 months after surgery shows satisfactory fusion at the C6-7 level, without the development of subsidence and junctional problems. D: Computed tomography image shows successful filling of bony tissue within the synthetic cage.

Table 4. Comparison of radiological results by cervical sagittal alignment $(\mathrm{CSA})$, segmental angle $(\mathrm{SA})$, and interbody height $(\mathrm{IBH})$

\begin{tabular}{|c|c|c|c|c|}
\hline & Preoperative & Postoperative & $\begin{array}{c}\text { Final follow- } \\
\text { up }\end{array}$ & $\begin{array}{c}p \text {-value } \\
\text { (I) }\end{array}$ \\
\hline SA (Group I) & $6.7 \pm 7.7$ & $-3.6 \pm 6.6$ & $0.6 \pm 7.7$ & $\begin{array}{r}<0.001^{*} \\
0.026^{\dagger}\end{array}$ \\
\hline SA (Group II) & $5.7 \pm 8.1$ & $-5.9 \pm 4.7$ & $-4.8 \pm 4.1$ & $\begin{array}{l}<0.001^{*} \\
>0.05^{\dagger}\end{array}$ \\
\hline$p$-value (II) & $>0.05$ & $>0.05$ & 0.018 & \\
\hline CSA (Group I) & $-6.7 \pm 14.9$ & $-11.7 \pm 11.4$ & $-10.1 \pm 9.1$ & $\begin{aligned} & 0.013^{*} \\
> & 0.05\end{aligned}$ \\
\hline CSA (Group II) & $-8.7 \pm 10.1$ & $-13.9 \pm 12.0$ & $-15.2 \pm 12.9$ & $\begin{aligned} & 0.005^{*} \\
> & 0.05\end{aligned}$ \\
\hline$p$-value (III) & $>0.05$ & $>0.05$ & $>0.05$ & \\
\hline IBH (Group I) & $36.6 \pm 4.7$ & $40.4 \pm 5.2$ & $37.5 \pm 2.8$ & $\begin{array}{r}<0.029^{*} \\
0.018^{\dagger}\end{array}$ \\
\hline IBH (Group II) & $36.4 \pm 3.0$ & $41.3 \pm 3.8$ & $40.4 \pm 3.3$ & $\begin{array}{l}<0.008^{*} \\
>0.05\end{array}$ \\
\hline$p$-value (IV) & $>0.05$ & $>0.05$ & 0.037 & \\
\hline
\end{tabular}

Values are presented as means \pm standard deviation. ${ }^{*}$ Comparison of preoperative and postoperative. ${ }^{\dagger}$ Comparison of postoperative and last follow-up. $p$-value (I) : comparison of SA, CSA, and IBH within the group. $p$-value (II) : comparison of SA between two groups. $p$-value (III): comparison of CSA between two groups. $p$-value (IV) : comparison of $\mathrm{IBH}$ between two groups

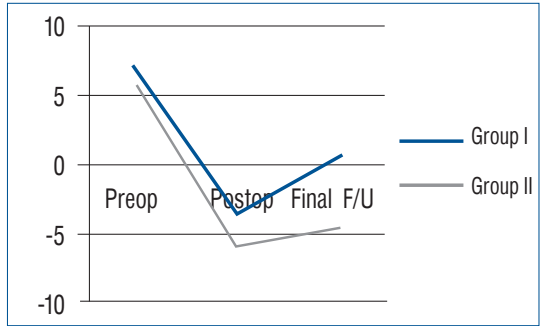

Table 4A. Graph for SA

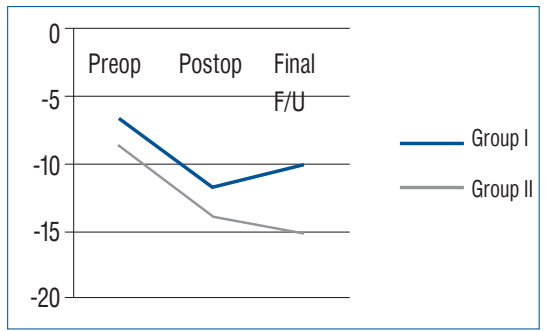

Table 4B. Graph for CSA

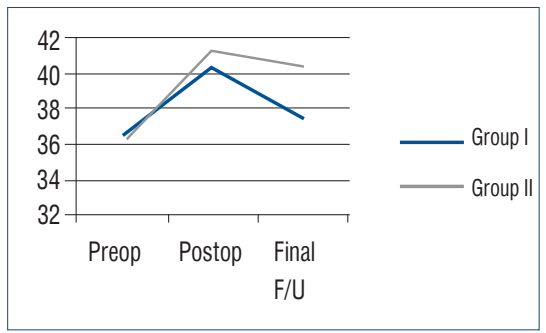

Table 4C. Graph for IBH 
Table 5. Development of radiologic and clinical adjacent segment degeneration (ASD)

\begin{tabular}{lcc} 
& \multicolumn{2}{c}{ Development of ASD } \\
\cline { 2 - 3 } & Radiologic ASD & Symptomatic ASD \\
\hline Group I & 9 & 0 \\
Group II & 2 & 0 \\
\hline$p$-value & 0.021 & \\
\hline
\end{tabular}

longed immobilization with a halo vest. Surgical stabilization has been reported using an anterior, posterior or a combined approach; however, the optimal approach remains controversial $^{7,9,26)}$. Although posterior stabilization techniques have been employed with good results, they are associated with several risks such as neurovascular damages, infection, postoperative neck pain with extensive muscle dissection, and blood loss ${ }^{8,25}$. Moreover, the incidence of disc disruption may be as high as $40 \%$ in cases of unilateral facet dislocation and $80 \%$ in cases of bilateral cervical facet dislocation ${ }^{23)}$. This could cause neurological deterioration, and the additional risk of anterior collapse of the disc space could lead to kyphotic deformity ${ }^{12}$. On the contrary, anterior fixation reduces the risk of catastrophic neurological complications and provides satisfactory stabilization for management of these injuries ${ }^{14,29)}$. Additional plate fixation after ACDF could provide effective stabilization with the advantage of only one-motion segment fusion in cervical facet dislocation. If decompression of the spinal cord is required, it is typically best accomplished using an anterior approach $^{3}$. We have almost always encountered grossly disrupted discs during anterior surgery; therefore, we prefer the anterior approach. Biomechanical investigations have demonstrated that ACDF with plating can effectively stabilize the non-osteoporotic cervical spine after complete posterior element injury ${ }^{19)}$. In this study, all patients underwent successful reduction and stabilization through the anterior approach, and there was no instability at the last follow-up. Therefore, ACDF with additional plating could be an excellent treatment option for traumatic subaxial cervical injury.

The risk of autograft donor-site morbidity, especially donor site pain, has been widely reported, suggesting the need for an alternative fusion method that obviates iliac crest harvest. Allograft has been used as an alternative material, although it has less osteoinductive potential and is associated with lower fusion rates ${ }^{2,5}$. Synthetic interbody cages have been developed to achieve immediate stability and successful bone fusion ${ }^{6,22)}$. Many of the complications associated with iliac crest harvest have been significantly reduced with the use of cages. The elasticity modulus is close to that of bone, resulting in minimizing subsidence and optimizing the interaction of compressive forces at the graft-host interface. In many studies, the cages were packed with autologous cancellous bone, which can be harvested via a smaller incision ${ }^{26)}$. This may reduce donor site morbidity because of its minimal invasiveness and maintenance of the integrity of the iliac crest ${ }^{15)}$. However, donor site pain still remains high and compromises the satisfactory clinical result of decompression ${ }^{20,28)}$. Recently, DBM was introduced as an osteoinductive substance that contains bone morphogenic proteins. Moreover, some kinds of DBM not only have osteoinductive capability but also osteoconductive capability. Therefore, the use of DBM for fusion can obviate cancellous bone harvest of the iliac crest. In our study, 100\% fusion rate was achieved by the use of PEEK cage with DBM (Group II) at 12 months after surgery. Although the fusion rate in patients in whom iliac crest autograft was used (Group I) was $100 \%$ at 12 months after surgery, $32 \%$ of the patients reported residual pain at the bone harvest site. Therefore, we speculate that PEEK cage with DBM was as effective as iliac autograft for anterior cervical fusion, while avoiding donor site morbidity.

To the best of our knowledge, few studies have compared the differences between autologous bone graft and synthetic cage in ACDF with plate system. In this study, we compared the surgical results with regard to clinical and radiologic findings. There was no difference in the clinical outcome between the groups. The improvement in Frankel grade did not differ between the groups before surgery and at the last follow-up. No differences were observed in the changes in the VAS score of neck pain between the groups. Chronic donor site pain could be eliminated using PEEK cage with DBM in group II.

With regard to radiologic results, the fusion rate, cervical alignment, and the development of ASD were considered. As previously mentioned, complete bone fusion was achieved in all 70 patients in this study at 12 months after surgery. Unfortunately, we did not calculate the exact time required for fusion in both the groups. However, another study reported that the time required for solid fusion from surgical fusion was similar in traumatic cervical injury between the autograft and synthetic cage groups ${ }^{26)}$. In cervical alignment, the SA of fu- 
sion level and CSA were increased in both groups after surgery; however, the parameters were well maintained in Group II without significant correction loss, compared with Group I. The results may be associated with the subsidence or graft collapse in iliac autografts. In Group I, the IBH of the fused segment at the last follow-up was decreased by about $2.9 \mathrm{~mm}$, compared with the value immediately after surgery. However, the IBH was decreased by only about $0.9 \mathrm{~mm}$ in Group II. This fact indicated that more graft collapse was observed in Group I compared with the subsidence of cage in Group II. Yamagata et al. ${ }^{30)}$ advocated that cage or graft subsidence resulted in early or late deterioration of the local cervical angle and overall cervical alignment. Therefore, graft collapse might have more frequently developed in Group I than in Group II, and it might have been influenced by the negative effect to maintain the SA and CSA after surgery. Patients in Group I also frequently developed radiologic ASD. However, no patient required revision surgery to ASD until the last follow-up, because the symptomatic ASD went unnoticed. The development of radiologic ASD might be associated with graft collapse and loss of cervical alignment. The graft collapse in Group I can lead to impingement of the plating on the adjacent disc spaces, and it might promote or accelerate disc degeneration $^{16)}$. Further, SA and CSA were decreased during the follow-up period in Group I, which means that the loss of SA and CSA may lead to the loss of cervical lordosis and, consequently, cervical malalignment. Park et al. ${ }^{18)}$ reported that malalignment of the cervical spine related with loss of cervical lordosis affects the radiologic or clinical outcomes related to adjacent segment pathology.

Although our clinical results regarding neck pain and Frankel grade did not significantly differ between the groups, patients from Group II showed better radiologic results in terms of cervical alignment and the development of ASD. Therefore, with advantages such as no donor site morbidity and no graftrelated complications, synthetic cage filled with DBM and plate is a promising surgical option for fixation of single-level subaxial cervical spine injuries.

Our study had several limitations. First, it was designed retrospectively, which could introduce selection bias owing to poor record keeping. Second, the study population was relatively small. However, the majority of data showed normal distribution in statistical analysis, and non-parametric test was used for analysis of some data such as Frankel grade and
VAS score. Finally, this study did not include a cost-effectiveness analysis. However, hospital stay and cost mostly depended on the severity of concomitant spinal cord injury and not on the surgical method used in traumatic cervical injury; therefore, the investigation of cost-effectiveness may be not important in this study.

\section{CONCLUSION}

ACDF using a PEEK cage with DBM followed by anterior plating in subaxial cervical injury showed high fusion rates and a satisfactory clinical outcome without any donor site morbidity. Radiologically, it showed more advantages in maintenance of IBH and cervical alignments than those shown by ACDF using autologous iliac bone grafts. Moreover, a higher incidence of radiologic ASD was observed among patients in whom autologous iliac bone grafts were used. Therefore, ACDF using a PEEK cage with DBM followed by anterior plating can replace the traditional interbody fusion with autologous bone graft in subaxial cervical spine injuries. Prospective randomized studies on a large number of patients are warranted to support the results of this study.

\section{- Acknowledgements}

This study was financially supported by Chonnam National University, 2011.

\section{References}

1. Aebi M : Surgical treatment of upper, middle and lower cervical injuries and non-unions by anterior procedures. Eur Spine J 19 Suppl 1 : S33S39, 2009

2. Bishop RC, Moore KA, Hadley MN : Anterior cervical interbody fusion using autogeneic and allogeneic bone graft substrate : a prospective comparative analysis. J Neurosurg 85 : 206-210, 1996

3. Bohlman $\mathrm{HH}$ : Acute fractures and dislocations of the cervical spine. An analysis of three hundred hospitalized patients and review of the literature. J Bone Joint Surg Am 61 : 1119-1142, 1979

4. Bracken MB, Shepard MJ, Collins WF, Holford TR, Young W, Baskin DS, et al. : A randomized, controlled trial of methylprednisolone or naloxone in the treatment of acute spinal-cord injury. Results of the second national acute spinal cord injury study. N Engl J Med 322 : 1405-1411, 1990

5. Cauthen JC, Kinard RE, Vogler JB, Jackson DE, DePaz OB, Hunter OL, et 
al. : Outcome analysis of noninstrumented anterior cervical discectomy and interbody fusion in 348 patients. Spine (Phila Pa 1976) 23 : 188192, 1998

6. Cho DY, Liau WR, Lee WY, Liu JT, Chiu CL, Sheu PC : Preliminary experience using a polyetheretherketone (PEEK) cage in the treatment of cervical disc disease. Neurosurgery 51 : 1343-1349; discussion 13491350,2002

7. Du W, Wang C, Tan J, Shen B, Ni S, Zheng Y : Management of subaxial cervical facet dislocation through anterior approach monitored by spinal cord evoked potential. Spine (Phila Pa 1976) 39 : 48-52, 2014

8. Fazl M, Pirouzmand F : Intraoperative reduction of locked facets in the cervical spine by use of a modified interlaminar spreader : technical note. Neurosurgery 48 : 444-445; discussion 445-446, 2001

9. Feng $G$, Hong $Y$, Li L, Liu H, Pei F, Song Y, et al. : Anterior decompression and nonstructural bone grafting and posterior fixation for cervical facet dislocation with traumatic disc herniation. Spine (Phila Pa 1976) 37 : 2082-2088, 2012

10. Frankel HL, Hancock DO, Hyslop G, Melzak J, Michaelis LS, Ungar GH, et al. : The value of postural reduction in the initial management of closed injuries of the spine with paraplegia and tetraplegia. I. Paraplegia 7 : 179-192, 1969

11. Garvey TA, Eismont FJ, Roberti LJ : Anterior decompression, structural bone grafting, and Caspar plate stabilization for unstable cervical spine fractures and/or dislocations. Spine (Phila Pa 1976) 17 : S431-S435, 1992

12. Hadley MN, Fitzpatrick BC, Sonntag VK, Browner CM : Facet fracturedislocation injuries of the cervical spine. Neurosurgery $30: 661-666$, 1992

13. Hilibrand AS, Carlson GD, Palumbo MA, Jones PK, Bohlman HH : Radiculopathy and myelopathy at segments adjacent to the site of a previous anterior cervical arthrodesis. J Bone Joint Surg Am 81 : 519-528, 1999

14. Kim KH CD, Sung JK : The management of bilateral interfacetal dislocation with anterior fixation in cervical spine : comparision with combined antero-posterior fixation. J Korean Neurosurg Soc 42 : 305-310, 2007

15. Kulkarni AG, Hee HT, Wong HK : Solis cage (PEEK) for anterior cervical fusion : preliminary radiological results with emphasis on fusion and subsidence. Spine J 7 : 205-209, 2007

16. Ning X, Wen Y, Xiao-Jian Y, Bin N, De-Yu C, Jian-Ru X, et al. : Anterior cervical locking plate-related complications; prevention and treatment recommendations. Int Orthop 32 : 649-655, 2008

17. Oh HS, Shim CS, Kim JS, Lee SH : Clinical and radiological comparison of femur and fibular allografts for the treatment of cervical degenerative disc diseases. J Korean Neurosurg Soc 92 : 18-23, 2013
18. Park MS, Kelly MP, Lee DH, Min WK, Rahman RK, Riew KD : Sagittal alignment as a predictor of clinical adjacent segment pathology requiring surgery after anterior cervical arthrodesis. Spine J 14 : 1228-1234, 2013

19. Paxinos O, Ghanayem AJ, Zindrick MR, Voronov LI, Havey RM, Carandang $G$, et al. : Anterior cervical discectomy and fusion with a locked plate and wedged graft effectively stabilizes flexion-distraction stage-3 injury in the lower cervical spine : a biomechanical study. Spine (Phila Pa 1976) 34 : E9-E15, 2009

20. Rawlinson JN : Morbidity after anterior cervical decompression and fusion. The influence of the donor site on recovery, and the results of a trial of surgibone compared to autologous bone. Acta Neurochir (Wien) 131 : 106-118, 1994

21. Reindl R, Ouellet J, Harvey EJ, Berry G, Arlet V : Anterior reduction for cervical spine dislocation. Spine (Phila Pa 1976) 31 : 648-652, 2006

22. Riew KD, Rhee JM : The use of titanium mesh cages in the cervical spine. Clin Orthop Relat Res : 47-54, 2002

23. Rizzolo SJ, Piazza MR, Cotler JM, Balderston RA, Schaefer D, Flanders A : Intervertebral disc injury complicating cervical spine trauma. Spine (Phila Pa 1976) 16 : S187-S189, 1991

24. Robertson PA, Ryan MD : Neurological deterioration after reduction of cervical subluxation. Mechanical compression by disc tissue. J Bone Joint Surg Br 74 : 224-227, 1992

25. Shapiro S, Snyder W, Kaufman K, Abel T : Outcome of 51 cases of unilateral locked cervical facets : interspinous braided cable for lateral mass plate fusion compared with interspinous wire and facet wiring with iliac crest. J Neurosurg 91 : 19-24, 1999

26. Song KJ, Choi BW, Kim GH, Song JH : Usefulness of polyetheretherketone (PEEK) cage with plate augmentation for anterior arthrodesis in traumatic cervical spine injury. Spine J $10: 50-57,2010$

27. Thome C, Krauss JK, Zevgaridis D : A prospective clinical comparison of rectangular titanium cages and iliac crest autografts in anterior cervical discectomy and fusion. Neurosurg Rev 27 : 34-41, 2004

28. Vavruch $L$, Hedlund $R$, Javid $D$, Leszniewski W, Shalabi A : A prospective randomized comparison between the cloward procedure and a carbon fiber cage in the cervical spine : a clinical and radiologic study. Spine 27 : 1694-1701, 2002

29. Vital JM, Gille 0 , Senegas J, Pointillart V : Reduction technique for uniand biarticular dislocations of the lower cervical spine. Spine 23 : 949 954; discussion 955, 1998

30. Yamagata T, Takami T, Uda T, Ikeda H, Nagata T, Sakamoto S, et al. : Outcomes of contemporary use of rectangular titanium stand-alone cages in anterior cervical discectomy and fusion : cage subsidence and cervical alignment. J Clin Neurosci 19 : 1673-1678, 2012 